\title{
2 \\ El valor del socio en la cultura cooperativa
}

Dr. Tulio Rosembuj

1. El núcleo de la sociedad cooperativa es el socio. Y su finalidad, por tanto, no puede ser otra que la de su servicialidad a los intereses económicos y personales que persigue. La cooperativa como instrumento inmediato y directo de satisfacción de necesidades humanas se construye en torno a dos ejes.

Primero, la cooperativa del socio es propiedad privada de los socios en proporción a sus operaciones y en base a la actividad desarrollada.

Segundo, la cooperativa del socio es un medio de valoración de los socios que la integran, de cada uno según su esfuerzo a cada uno según su valor añadido, que no de la aportación al capital social'.

Es por ello que el valor cooperativo consiste en dar valor al socio, a la persona, puesto que es la masa crítica de la que depende la cooperativa para subsistir y crecer. Y, a la vez, su desvalor condenará al fracaso la supervivencia del valor cooperativo.

El valor cooperativo, en una primera aproximación, estriba, precisamente, en la diversidad de la causa del contrato respecto a cualquier otra sociedad ordinaria: la distribución del excedente en proporción a la actividad del socio, que no de la aportación al capital social. Y esto está directamente vinculado al valor capital del socio y al conjunto del capital intelectual de la cooperativa.

El paradigma es simple: el valor cooperativo está determinado por el valor del socio, en singular y pluralmente, y, en su consecuencia, su

1 Rosembus T., La organización jurídica de la cooperativa en España y sus consecuencias económicas, en Economía social y empresa, Barcelona, 1995, p. 144 y «Rein-

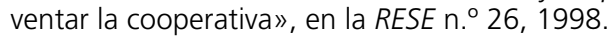


fortalecimiento decidirá la calidad (competitividad) de la entidad. O dicho en otras palabras: la cooperativa tiene el valor que le consagran sus socios y el valor cooperativo es una mera prolongación del capital humano e intelectual de los que lo practican.

No hay un valor ecuménico del cooperativismo, despegado de la aquilatación (del valor) de los que son sus actores.

2. El principal activo de la cooperativa no es su inmovilizado material, sino el capital humano e intelectual disponible. El valor del socio es un activo intangible e inmaterial, un patrimonio que no es material o físico.

Justamente, el valor del socio es el principal capital intelectual de la cooperativa (intangible assets) y su protección, permanencia, estímulo implica la debida satisfacción económica, social y personal de los intereses que se pretenden.

La conservación, reintegración, recuperación del capital (humano) intelectual aparece, entonces, como una referencia insoslayable en términos, repárese, de valor cooperativo.

El capital intelectual, en la definición del High Level Expert Group de la Comisión de la Unión Europea consiste en «los factores no materiales que contribuyen a la prestación de la empresa en la producción de bienes o en la oferta de servicios o que se considera pueden generar beneficios económicos futuros a la entidad o a los individuos que controlan tal despliegue $»^{2}$.

De modo que, la distribución del excedente en proporción a la actividad del socio en la cooperativa debe ser, al mismo tiempo, un factor de discriminación positiva de su valor capital en orden a su capacidad, de obrar, su capacidad de hacer, su capacidad de realización, su capacidad de imaginación, su capacidad de innovación.

En suma, cada socio es un patrimonio de conocimientos, competencias, relaciones, know-how que determinando su valor, representa, en su conjunto, la especificidad cultural de la cooperativa y, por extensión el valor cooperativo ${ }^{3}$.

2 European High Level Group-DG Enterprise. The intangible economy. Impact and policy issues. Report. 10/200.

3 SVEIBY K. E., The new organizational wealth, San Francisco, 1998. 
El paradigma es: la cooperativa vale cuanto el complejo de conocimientos y relaciones de sus socios susceptibles de transformarse en valor, interno o externo, en el mercado, a paridad de circunstancias.

La fuente de valor de cualquier organización en general y de la cooperativa en particular está en la creación y distribución de conocimiento. Y para que ello se produzca, es condición ineliminable la participación económica del socio en la actividad de la cooperativa y su derecho a las ventajas patrimoniales que emergen de la relación ${ }^{4}$.

3. El capital intelectual define el valor de una determinada organización del conocimiento, en términos de capital humano, capital relacional, capital organizativo.

La unidad de medida no es el dinero, como es lo propio de la contabilidad financiera, sino que es alternativa y diversa según el origen del capital intangible, basada en índices de crecimiento, eficiencia y estabilidad. A título de ejemplo en el capital humano: porcentaje de la facturación invertida en formación, valor añadido por persona, porcentaje de los colaboradores que sugieren nuevas iniciativas, inversión per cápita en formación, nuevas ideas y productos, etcétera.

La plataforma de valor (value platform) identifica la contribución al conjunto de la preparación, pericia y habilidad de las personas; los procedimientos de información y decisión, los procesos de producción y venta de la empresa y, por último, las relaciones con los usuarios clientes, proveedores e inversores.

En suma, el valor de la organización está estrechamente vinculado a la creación de valor por sus integrantes. El valor resultante representa a los individuos, que actúan, que crean sistemas, que se conectan con el mercado.

«El flujo lógico de creación de valor en una empresa parte del capital humano, o del conjunto de las competencias, del know-how y de las características personales de los individuos que operan en el interior de la organización. Tal capital debe poderse transformar en capital organizativo, o sea, un añadido de orden superior que consiente a la empresa de apropiarse de tales competencias y know-how a un nivel de estructura. Un conocimiento que pasa del conocimiento de una persona a un banco de datos de la empresa es

4 Buonocore V., Diritto alla cooperazione, Bologna, 1997, p. 150. 
un ejemplo de creación de valor del capital humano a capital organizativo. El paso último es la transformación de dicho capital en capital relacional, es decir, atraer clientes y conservarlos, proveedores, inversores ${ }^{5} . »$

4. La cooperativa del socio se confronta con la cooperativa sin socios (Spada), una empresa que pertenece a los gestores, sin que esté a disposición de los cooperativistas: una organización apta para diseños económicos, sociales, culturales, que desconsidera su primera obligación hacia los socios que la crearon y mantienen viva.

No es nuevo en la doctrina el interrogante que se formula, en torno a la insuficiencia de tratamiento, en la materia de los derechos del socio a las ventajas patrimoniales de la cooperativa, que es de su propiedad. La gestión de servicios no supone, sino la servidumbre de la entidad a la definición y práctica de los socios. La cooperativa es una empresa órgano de integración de la economía de los socios. Y su finalidad es la sustitución (en el mercado) del lucro intermediario, para su atribución: el fundamento de la ventaja patrimonial del socio, ya como ahorro en el gasto o mayor retribución o, al límite, como legítimo titular de reservas, es consecuencia de su actividad personal y, antes, de la apropiación del margen de beneficio de la actividad económica que ha sido objeto de la sustitución. La valoración del excedente y su destino aparece como el más importante desafío en la cultura cooperativa del siglo XXI.

En otros términos, se vuelve a la dicotomía: la cooperativa del socio o la cooperativa sin socio ${ }^{6}$.

Si, como aquí se sostiene, la cooperativa está para dar valor al socio, y no a la inversa, resultará que el instrumento primordial para que ello ocurra o, al menos uno de los instrumentos, no es sino el retorno.

El retorno es el núcleo esencial de la cooperativa. Primero, porque señala la diferencia respecto a cualquier otra sociedad ordinaria. Segundo, porque mide la proporción singular de cada socio en la actividad cooperativizada. Tercero, porque, atendiendo lo dicho, establece el pleno derecho del socio al goce y disfrute del capital intelectual, del valor que ha creado.

5 Gravera, Maglione, Ruggerl., La valutazione del capitale intellettuale, Milano, 2001, p. 68.

6 BAssi A., Dividendi e ristorni nalle società cooperative, Milano, 1979, p. 6. 
5. El retorno es la compensación diferida de las prestaciones del socio, en base a las compras efectuadas (cooperativas de consumo), al valor de los bienes y servicios aportados (cooperativas de producción) o a la magnitud y calidad del trabajo (cooperativas de trabajo asociado). El retorno, es una figura exclusiva de la cultura cooperativa, no habiendo merecido, sin embargo, profundidad en su tratamiento ${ }^{7}$, que sostiene que el retorno no es el criterio de la cooperación, o, más recientemente ${ }^{8}$ donde califica el tema del retorno como problema abierto en la doctrina.

No es equivalente al dividendo, porque no está relacionado con el capital suscrito o desembolsado; pero, tampoco, puede considerarse que el retorno no debe ser algo más que la devolución o reembolso del ahorro de gasto o aumento de retribución al socio durante un período de tiempo determinado.

El excedente de la cooperativa, para comenzar, una vez aplicados los gastos necesarios para su obtención y las sumas afectadas al reemplazo o renovación del activo inmovilizado; pertenece a sus dueños, los socios. El derecho (del socio) a su valor (económico) es pleno.

Todo aquello que no es necesario e inherente a la organización, es retorno, o, lo que es lo mismo, derecho a la ventaja patrimonial originada por la actividad del socio en la cooperativa.

El excedente (neto) atribuible al socio, puesto que la cooperativa es su extensión en el mercado, no puede identificarse con el reparto de beneficio o utilidades propias de la sociedad ordinaria; pero, tampoco puede restringirse a la mera restitución de lo pagado o cobrado de más o de menos ni, tanto menos, que sea un saldo deudor de la retribución practicada por la prestación cooperativa9 ${ }^{9}$.

El retorno, en mi opinión, es el fruto (civil) del capital intelectual, actual y pasado, de la cooperativa.

No es un beneficio-dividendo porque excluye su referencia a la parte del capital aportado; pero, es un fruto de un patrimonio intangible aportado y sostenido en la cooperativa.

7 V. P. LAMBERT, La doctrina cooperativa, Bs. As. 1961, p. 77.

8 M. L. Llobregat HuRTAdo, Mutualidad y empresas cooperativas, Barcelona, 1990, p. 425.

9 V. BuONoCore, Cooperazione e cooperative, 1977, p. 145. 
En sentido estricto, el retorno es la devolución o reembolso del valor capital (intelectual) creado por el socio. Curiosamente, la jurisprudencia suprema, al calificar el retorno como rendimiento del capital mobiliario lo hace con referencia al acervo y patrimonio de la cooperativa. En verdad, el retorno tiene por fuente el caudal o conjunto de bienes no materiales ni físicos, que son la consecuencia de la energía del socio en su consecución. (STS 25-3-86).

El excedente obtenido por la cooperativa, es, en el sentido expresado, retorno del socio sea con destino a la reserva legal o a su distribución inmediata.

El retorno puede concebirse como la forma cooperativa inédita - el valor del cooperativismo- en el reconocimiento del capital intelectual, su conservación y recuperación.

El valor fortalecido es el de la autoayuda. El socio, que es el origen del valor de la cooperativa, transforma recursos que no son permanentes en fuentes de ventajas patrimoniales. El no capital se convierte merced a su propio esfuerzo en valor capital (intelectual), cuyo fruto o contraprestación es el retorno.

El retorno sirve a compensar, en general, la opción de ser y hacer cooperativa, apreciando el coste de oportunidad que supone la actividad en alternativa a otras.

El retorno como fruto (civil) del capital intelectual recala en la aplicación del art. 355 del Código Civil: derecho de crédito que se tiene a cambio de una contraprestación o créditos a favor del que ha de percibirlos, en dinero o en especie ${ }^{10}$.

Y la retribución del capital (intelectual), no empresarial ni profesional, significa un producto que emana del valor capital del socio, sea como conocimiento y experiencia, organización o relación desde el mercado.

El conocimiento como producto del capital-conocimiento no es desconocido en el derecho positivo. La asistencia técnica no vinculada al ejercicio de una actividad económica del que la presta es, en el derecho tributario, un rendimiento del capital mobiliario, sea en el plano de estudios, ordenamiento de instalaciones o perfeccionamiento de la producción ${ }^{11}$.

10 Díez-Picazo-Gullón, Sistema de derecho civil, Madrid, 1982, p. 431, Alonso Pérez, Comentarios al Código Civil M. Albaladejo, Madrid, 1980, V 1.ํ, p. 205.

11 LIRPF art. 23.4.b. 
Al calificar la jurisprudencia suprema al retorno como capital mobiliario, de cara a la renta de la persona física, adopta como fundamento que su fuente es el acervo o patrimonio social de la cooperativa, de donde no resulta difícil inferir que el acervo expresa el conjunto de bienes inmateriales, mientras que el patrimonio alude a los bienes físico y materiales. El retorno no es contraprestación del trabajo personal del socio que la recibe por otro conducto en forma de sueldo o salario ni es remuneración directa de los servicios prestados a la entidad como directores, gestores, consejeros, administradores o empleados. Por tanto, el retorno es fruto (civil) de algún capital que no es evidentemente financiero - porque no tendría sentido-, sino de otra naturaleza no dineraria: el acervo o caudal del capital intelectual.

6. El retorno actual o histórico es fruto (civil) del capital intelectual, del socio. La transformación del excedente íntegro en neto libe$\mathrm{ra}$, en su favor, la suma de los excedentes precedentes y actuales ${ }^{12}$. Sólo así puede apreciarse la concepción de la cooperativa como extensión del socio, para la eliminación intermediaria, y el transporte del margen de utilidad sustituido a la satisfacción de sus necesidades.

Todo el excedente neto es retorno, excepto la reserva legal que debería ajustarse al régimen de reserva legal de cualquier otra sociedad mercantil, a menos que se aspire al disfrute de algún beneficio fiscal o ayuda estatal. Y, aún así, con reticencias, si se parte de la premisa que no parece adecuado técnicamente proteger a la sociedad, sino al socio que es el eje ${ }^{13}$.

El retorno se configura, entonces, como la compensación de las prestaciones del socio con la cooperativa y en su proporción: el fruto (civil) del capital intelectual acumulado.

La canalización del retorno depende del tipo cooperativo. Siguiendo la doctrina de A. Bassi, cuando diferencia entre cooperativa de consumo (vivienda, crédito, seguros) y de producción y trabajo (trabajo asociado, agraria), no será igual el retorno vinculado al capital rela-

12 Rosembus T., «Reinventar la cooperativa», RESE n. 26 1998; «En suma la reserva debería ser repartible entre los socios que contribuyen a su formación. Si esto se produce desde el momento de la constitución, perteneciendo a los socios que la han visto crecer de su esfuerzo y sacrificio, nada hay en la cooperativa que no sea del socio enfatiza el valor moral del capital como trabajo acumulado...»

13 Rosembuj T., «Notas sobre la cooperativa, el socio y la norma tributaria», en Boletín de la Asociación Internacional de Derecho Cooperativo, Deusto, 2000. 
cional del conjunto del capital intelectual, que el que se aplica al capital humano y organizativo.

El primer retorno se apoya en la solicitud y demanda del socio de las prestaciones sociales. Es el ejemplo del socio-usuario, la satisfacción, el porcentaje de compras, el grado de fidelidad, etcétera.

El segundo retorno, se sustenta en la obligación del socio de la prestación cooperativa, sea por el trabajo o el suministro o provisión de bienes o servicios. Es el ejemplo, del socio y su formación, iniciativas, ideas, valor añadido.

En el retorno al consumo la valoración, predominante, del capital relacional obliga, también, en sentido totalizador, a retribuir al socio en sus necesidades personales de asistencia sanitaria, formación, complemento de pensiones, accidentes. El retorno cooperativo no ofrece sólo descuentos al cliente, sino medios de valorización de su propia existencia y de su familia.

En el retorno a la producción y al trabajo la valoración, prevalente, del capital humano y organizativo obliga, sobre todo, a la retribución del conocimiento continuo, de la innovación aportada, de la pericia puesta en práctica.

El retorno, en consecuencia, no sólo atiende a la necesidad monetaria, sino a la función de bienestar del socio en su dimensión inmaterial.

En el fondo es el descuento para la educación previsto en los Estatutos de Rochdale, con la finalidad del perfeccionamiento intelectual de los miembros y de la parte de su familia a cargo, para el mantenimiento de la biblioteca y para la creación de otros medios de instrucción que puedan considerarse deseables; descuento del 2,50 \% de los excedentes netos (art. 42). La diferencia es que, para los que creemos en la cooperativa como medio de satisfacción de las necesidades de los socios: la retribución en especie directa e inmediata pertenece al ámbito de sus autoresponsabilidades indelegables, sin que sea preceptivo su acumulación previa en reserva.

La recuperación del capital intelectual advierte sobre la transitoriedad del valor creado. En efecto, el capital intelectual, como cualquier otro capital, no es, por definición permanente. Ello también ocurre con el capital humano, organizativo, relacional. La amortización debe proveer a su reintegración al final de su vida útil, por cambio imprevisibles o, el envejecimiento de los socios, de las ideas, de la creatividad. 
No obstante, la medida de los intangibles assets y su contabilización está en los inicios. Las nuevas formas de medir el valor que no reposa en la materia; comienza. Esta renta cooperativa que está condicionada por el capital intelectual del socio y en proporción al uso de la gestión de servicios y depende del esfuerzo perseverante, la educación y la responsabilidad.

La pregunta es si ésta renta de cooperación tiene o no propietario o es un dominio público o colectivo.

La respuesta es, a mi parecer, obvia: la renta de cooperación sea positiva o negativa, pertenece al socio ${ }^{14}$. La renta de la cooperativa es renta de los cooperativistas, que pueden de esta forma incrementar o no su renta personal e individual, en función de los rendimientos positivos o negativos obtenidos a través de su empresa.

El quantum de la renta del socio es total y global, una vez deducidos los gastos necesarios para su obtención y conservación y dotadas las reservas legales preceptivas, que no debieran ser como ahora, irrepartibles e indisponibles en términos tan diferentes a cualquier otra sociedad mercantil. La cooperativa no es una fundación gestionada por una asociación: es una empresa privada de los socios que se abre al mercado de una sola parte, porque «en la parte opuesta son los socios los que la proveen de colaboración en términos de ${ }^{15}$ riqueza no valoraba monetariamente, porque antes no lo era en el mercado.

14 Botterl, T., Economía cooperativa Parma, 1983: «Por tanto, la cooperativa no realiza un verdadero lucro en sentido técnico, sino que produce una renta que se transfiere directamente sobre los socios».

15 R. BARRE, Economía Política 1, Barcelona 1965, p. 127: Hay que tener en cuenta los riesgos de accidentes, de enfermedades, la vejez, la formación profesional y cultural del individuo. Puede existir un uso normal o anormal y también puede hablarse de envejecimiento del capital humano (envejecimiento de las personas, inadaptación a las tareas, rutina e inercia espiritual), etc.; LANCASTER K., Economía moderna 1, 1977, p. 445: «En una economía de mercado, el capital humano puede ser analizado en cierto modo de forma análoga al capital físico... las cualificaciones adquiridas por medio de la formación profesional han venido a denominarse capital humano» (448); Lev. Baauch.Communicating knowiedge capabilities, N.Y. University. Stem Schoof of Business: "sostener que los activos materiales deben medirse y valorizarse mientras los intangibles no equivale a sostener que las "cosas" tienen valor mientras las "ideas" no"; STEWART T.A., Intellectual capital: the new wealth of organisation, New York, 1997; EDVINSSON-MALONE, Intellectual capital: realizing your company's real value by finding its hidden root, New York, 1997); G.G. LoMBARDI, The value matrix. A new binary model of economic and cultural value. Milano, 2001. 